\title{
West Haven Hepatic Encephalopathy Grade 0
}

National Cancer Institute

\section{Source}

National Cancer Institute. West Haven Hepatic Encephalopathy Grade O. NCI Thesaurus. Code C117824.

Minimal - symptoms or pathological characteristics include minimal hepatic encephalopathy, lack of detectable changes in personality or behavior, minimal changes in memory, concentration and intellectual function, and absence of coordination asterixis. (Adapted from: Hepatic Encephalopathy. David C Wolf. http://emedicine.medscape.com/article/186101-overview) 